Article

\title{
Formulation of Laurus nobilis Essential Oil Nanoemulsion System and Its Application in Fresh-Cut Muskmelons
}

\author{
Qiaomei Ru*, Qiong Hu, Chengen Dai, Xuebing Zhang and Yan Wang
}

Citation: Ru, Q.; Hu, Q.; Dai, C.; Zhang, X.; Wang, Y. Formulation of Laurus nobilis Essential Oil

Nanoemulsion System and Its

Application in Fresh-Cut

Muskmelons. Coatings 2022, 12, 159.

https://doi.org/10.3390/

coatings12020159

Academic Editor: Raffaele Porta

Received: 10 November 2021

Accepted: 24 January 2022

Published: 27 January 2022

Publisher's Note: MDPI stays neutral with regard to jurisdictional claims in published maps and institutional affiliations.

Copyright: (C) 2022 by the authors. Licensee MDPI, Basel, Switzerland. This article is an open access article distributed under the terms and conditions of the Creative Commons Attribution (CC BY) license (https:// creativecommons.org/licenses/by/ $4.0 /$ )
Department of Health and Tourism, Hangzhou Wanxiang Polytechnic, Hangzhou 310023, China; huqiong@wxpoly.cn (Q.H.); daichengen2008@sohu.com (C.D.); hzxuebing@163.com (X.Z.); wangyan@wxpoly.cn (Y.W.)

* Correspondence: ruqm@wxpoly.cn; Tel.: +86-571-8577-6315

\begin{abstract}
The objective was to elucidate the influences of Laurus nobilis essential oil nanoemulsion on the quality properties of fresh-cut muskmelons (Cucumis melo L.) stored at $4{ }^{\circ} \mathrm{C}$ for 8 days. The $L$. nobilis oil nanoemulsion coating can inhibit changes in the browning index and titratable acidity level of muskmelon samples. The browning index in the slices treated with L. nobilis oil nanoemulsion was $0.095 \pm 0.007$, as compared with that of the control $(0.314 \pm 0.018)$. Meanwhile, L. nobilis oil nanoemulsion treatment maintained total phenolic content, with values ranging from $11.13 \pm 0.74 \mathrm{mg}$ GAE/g FW to $9.47 \pm 0.75 \mathrm{mg}$ GAE/g FW and inhibited the activities of related enzymes, such as polyphenol oxidase, peroxidase and antioxidant enzymes (catalase and peroxidase). Moreover, the application of $L$. nobilis oil nanoemulsion inhibited the proliferation of spoilage microorganisms. The population of the aerobic bacteria of the muskmelon samples subjected to L. nobilis oil nanoemulsion treatment was $5.14 \pm 0.47 \log \mathrm{CFU} / \mathrm{g}$ FW, whereas that of the control was $9.42 \pm 0.88 \log \mathrm{CFU} / \mathrm{g}$ FW after 8 days. Therefore, the tested L. nobilis oil nanoemulsion may contribute to the inhibition of surface browning and enhancement of the shelf life of fresh-cut muskmelons for eight days at refrigerator temperature.
\end{abstract}

Keywords: Laurus nobilis essential oil; nanoemulsion; fresh-cut muskmelon; browning inhibition; shelf life

\section{Introduction}

Muskmelons (Cucumis melo L.) are popular worldwide because of their unique flavor, taste and crispness. Lately, the market trend of fresh cut fruit and vegetables has greatly expanded due to the convenience of handling and eating and their fresh appearance. Owing to the growing requirement, fresh agricultural industrialists have represented interest in introducing muskmelons as fresh cut products.

Controlling fresh fruit quality, corruption and pathogen growth are the challenges faced by the fresh-cut fruit industry [1]. Therefore, using edible coating to increase the shelf life of fresh-cut fruit has been recommended. Edible coatings can be used as carriers of antimicrobial agents, antioxidants, anti-browning agents, flavoring agents and colorants that improve the nutritional, sensory and microbial properties of fresh-cut fruit [2].

Essential oils are commonly used as flavoring agents and have antibacterial activities against pathogenic microorganisms, but their application is limited in food processing because their water solubility is low and their volatility is high [3]. These limitations can be overcome by adding these compounds to edible coatings [4]. Moreover, the addition of surfactants to the biopolymer/essential oil mixture reduces the size of an emulsion, thereby providing additional benefits, such as improved water dispersibility and protection of essential oils from degradation $[3,4]$. For instance, the edible coatings of clove bud essential oil have been used in controlling foodborne bacteria (Salmonella Typhimurium and Listeria monocytogenes) in fresh-cut pak choi [5]. Chitosan-tea tree oil nanoemulsions have been used to increase the shelf life of fresh-cut red bell pepper [6]. Lemongrass essential 
oil antimicrobial nanoemulsions have used to improve safety and quality attributes of fresh-cut Fuji apples [7]. Orange peel essential oil microemulsions and nanoemulsions have been used to extend the shelf life of fresh-cut orange in pectin-based coating [8].

Laurus nobilis essential oil (LNEO) has a variety of biological activities, such as antioxidant, antifungal, antiviral, antibacterial and insecticidal activities, and has been widely studied and valued [9]. Its functional diversity is attributed to its abundant chemical components, which are composed of oxygen-containing monoterpenes, such as 1,8-cineole, terpinen-4-ol, methyl eugenol, linalool and syringa phenol [10]. Guar gum coating coupled with LNEO has been used to preserve unripe green mangoes during cold storage [11]. LNEO microemulsions show excellent antifungal activity in vivo and are effective in preventing the post-harvest decay of cherry tomatoes [12]. However, reports about the extension of fresh-cut muskmelons with LNEO emulsions are few. Therefore, in the current research, a LNEO nanoemulsion that can extend the shelf life of fresh-cut muskmelons was prepared.

\section{Materials and Methods}

\subsection{Materials}

White muskmelons (Cucumis melo L.) were brought from a wholesale fresh produce dealer in the fruit market of Hangzhou, Zhejiang, China. Pieces of fruit with the same shape, size (approximately $12 \mathrm{~cm}$ diameter) and color, without damage or injury, were selected and immediately conveyed to the lab.

LNEO was purchased from Shenzhen Guoxin Flavors and Fragrances Co., Ltd. (Shenzhen, China). Tween 80 was purchased from Aladdin Chemical Reagent Co., Ltd. (Shanghai, China). Folin-Ciocalteu reagent was purchased from Sigma Chemical Co. (St. Louis, MO, USA). Other chemicals and solvents used were of analytical grade.

\subsection{Construction of Pseudo-Ternary Phase Diagrams}

The formulation of the LNEO nanoemulsion was determined with a solubility study and constructed pseudo-ternary phase diagrams. Tween 80 and ethanol were selected as surfactant and co-surfactant, respectively. The oil phase was prepared by mixing ethanol and LNEO in a 3/1 $(v / v)$ ratio. Water was used as the aqueous phase. Tween 80 was used as the solvent system in the construction of a pseudo-ternary phase diagram in view of the solubility study in which the water titration method was used. The pseudo-ternary phase diagram was elaborated by mixing the oil phase with Tween 80 in 0:10, 1:9, 2:8, 3:7, 4:6, 5:5, $6: 4,7: 3,8: 2,9: 1$ and 10:0 ratios. Water was added dropwise to each oily mixture, and the mixtures were stirred with a magnetic mixer. All the samples were subjected to ultrasound treatment for $30 \mathrm{~min}$ for equilibration. The samples were allowed to equilibrate for $24 \mathrm{~h}$ before examining them. Each sample showed negligible evaporation loss. Samples that remained transparent and uniform after vigorous vortexing were considered to belong to the monophasic areas of the phase diagram.

\subsection{Characterisation of LNEO Nanoemulsion}

The phase separation and transparency of LNEO nanoemulsion were identified through visual inspection. The conductivity of the preparations at $10{ }^{\circ} \mathrm{C}$ was determined using a DDS-11A conductivity meter (Hangzhou Yamei Electronic Instrument Co., Ltd., Hangzhou, China). The particle size distribution, mean particle diameter and polydispersity index (PDI) of the LNEO nanoemulsion were determined through dynamic light scattering (DLS) analysis at $25{ }^{\circ} \mathrm{C}$ with a Zetasizer Nano-ZS90 (Malvern Instruments, Malvern, Worcestershire, UK). The analysis was performed at a scattering angle of $90^{\circ}$.

\subsection{Fruit Processing and Storage}

All the muskmelon fruits were washed with tap water, sanitised with a sodium hypochlorite solution for $5 \mathrm{~min}$, then washed with sterilised distilled water and dried with cold air. The fruit samples were peeled, and their cores were removed and cut into 
2-2.5 cm-thick slices with a sharp stainless steel knife. The pretreated fruit slices were randomly assigned to two groups. The control was immersed in sterilised distilled water, whereas the treatment group was immersed in LNEO nanoemulsion for 30 min at room temperature. All the samples were packed individually in polyethylene packaging bags and stored in an incubator at $4{ }^{\circ} \mathrm{C}$ for $0,2,4,6$ and 8 days successively. One piece (about 20 g) was packed in each bag. Fifteen coated and uncoated muskmelon slices were prepared, respectively. Three random samples were selected from each group every other day for analysis.

\subsection{Evaluation of Physicochemical Attributes}

\subsubsection{Firmness}

The texture of each muskmelon was measured using a TA-XT2i Texture Analyzer (Stable Micro Systems Ltd., England, UK). The measurement was based on the maximum penetration force required for a probe of $4 \mathrm{~mm}$ diameter to penetrate the cylinders $(20 \mathrm{~mm}$ high) to a $10 \mathrm{~mm}$ depth at a rate of $5 \mathrm{~mm} / \mathrm{s}$. Muskmelon pieces were placed perpendicularly to the probe for the penetration of their geometric centres. Three pieces (about $60 \mathrm{~g}$ ) each treatment were measured every time. Muskmelon pieces from each bag were ground after firmness and lightness were measured for the preparation of homogeneous samples.

\subsubsection{Lightness and Browning Index}

During the storage period, lightness changes in the slices were measured with a Minolta chroma meter (Model CR-400, Minolta, Tokyo, Japan) according to the method of Salvia-Trujillo et al. [7]. The $L^{* *}$ value was used as the indicator of cut-surface lightness intensity. The measurements were performed by placing the sample slices on a standard plate.

The browning index was measured according to the method depicted by Saxena et al. [13] and Sharma and Rao [14]. Briefly, $0.5 \mathrm{~g}$ of each sample was extracted in $5 \mathrm{~mL}$ of ethanol for $1 \mathrm{~h}$, then the extract was filtered. The browning index of the filtrate in terms of optical density $(\mathrm{OD})$ at $420 \mathrm{~nm}\left(\mathrm{~A}_{420}\right)$ was recorded.

\subsubsection{Total Soluble Solids (TSS), Titratable Acidity (TA) and Total Phenolic Content (TPC)}

The total soluble solids (TSS; Brix) and titratable acidity (TA) were expressed as citric acid equivalents and assayed with a pocket Brix-Acidity meter (PAL-BX/ACID F5, Atago Co., Ltd., Minato, Japan). Total phenolics content (TPC) was estimated using the FolinCiocalteu reagent method as described by Xu et al. (2015) [15]. The amount of TPC was expressed as milligrams of gallic acid equivalents per gram of fresh weight (mg GAE/g FW).

\subsection{Assay Activities of Enzymes}

Polyphenol oxidase (PPO) and peroxidase (POX) activities were determined according to the methods described by Zhu and Zhan [16] and Sharma and Rao [14], respectively. The activities of PPO and POX were expressed as U/g protein. Protein content was determined using the Bradford method with bovine serum albumin as standard [17].

Activities of phenylalanine ammonia lyase (PAL), peroxidase (POD) and catalase (CAT) were measured by using PAL, POD and CAT assay kits (Shanghai Solarbio Biotechnology Co., Ltd., Shanghai, China) in accordance with the instructions of the manufacturer, respectively. The activities of PAL, POD and CAT were expressed as U/g protein.

\subsection{Microbiological Evaluation}

The microbial quality of the fresh-cut muskmelon slices was determined in view of total aerobic plate count as well as yeast and mold counts with the pour plate technique [18]. Serial dilution samples were prepared by vigorously washing $25 \mathrm{~g}$ of muskmelon tissue in homogeneous bags with $225 \mathrm{~mL}$ of $1 \mathrm{~g} / \mathrm{L}$ sterile buffer peptone water at room temperature. Then, the microbes were inoculated into plate count agar at $36 \pm 1{ }^{\circ} \mathrm{C}$ for $48 \mathrm{~h}$ and potato 
dextrose agar at $28 \pm 1{ }^{\circ} \mathrm{C}$ for 5 days. After incubation, the number of colonies was calculated and expressed as logarithmic colony forming units per gram of fresh weight (log $\mathrm{CFU} / \mathrm{g}$ FW).

\subsection{Statistical Aanalysis}

Each measurement was carried out in triplicate, and results were presented as mean \pm standard deviation. SPSS 13.0 was used in performing analysis of variance (ANOVA). Differences were regarded as significant at $p$ value of $<0.05$.

\section{Results and Discussion}

\subsection{Construction of Pseudo-Ternary Phase Diagrams and Formulation of LNEO Nanoemulsions}

Emulsions can be formed in a range of surfactant-oil ratios, which are essential to the determination of particle size and emulsion stability [19]. Pseudo-ternary phase diagrams were constructed for the determination of the appropriate proportions of oil, surfactant and cosurfactant for the nanoemulsions. On the basis of the solubility study, Tween 80 was selected as the surfactant for pseudo-ternary phase diagram construction and formulation studies.

The solubility of LNEO was achieved by using ethanol as the cosurfactant, and the ratio of ethanol and laurel essential oil was 3:1. Nanoemulsion systems containing Tween 80 were prepared in different proportions. Most nanoemulsions were transparent and isotropic, and no phase transition was observed after centrifugation at $4000 \times g$ for $30 \mathrm{~min}$ (Figure 1). Given that Tween 80 negatively affected the antibacterial activity of essential oil emulsions [3], a low amount of Tween 80 showed better results. When the pseudoternary phase diagrams and when stability were considered, the selected nanoemulsion was composed of water aqueous $(99 \% w / w)$, Tween $80(0.6 \% w / w)$, ethanol $(0.3 \% w / w)$ and $\operatorname{LNEO}(0.1 \% w / w)$.

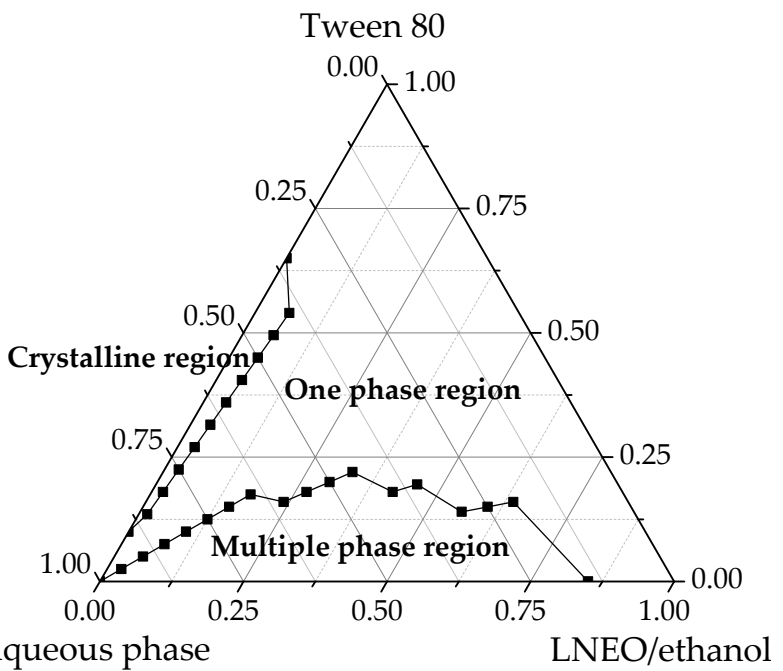

Figure 1. Pseudo-ternary phase diagram of the aqueous phase/Tween 80/ethanol/LNEO system.

\subsection{Physical Properties and Stability of the Prepared Nanoemulsions}

The freshly prepared nanoemulsion was transparent. Particle size distribution, average particle size and PDI are important indicators for describing the characteristics of emulsions, such as uniformity, dispersibility and stability [20]. The mean particle size of the nanoemulsion revealed by DLS measurements was $23.57 \pm 0.61 \mathrm{~nm}$. The peak width of the distribution diagram was very narrow, indicating that the particle size of the LNEO nanoemulsion was uniform. A PDI of $0.289 \pm 0.019$ revealed that the LNEO nanoemulsion droplets were dispersed, and particle adhesion and aggregation did not occur. The conductivity value of nanoemulsion was $447.6 \pm 9.2 \mu \mathrm{s} / \mathrm{cm}$. LNEO nanoemulsion can be determined as oil-in-water $(\mathrm{O} / \mathrm{W})$ nanoemulsions because of its high conductivity [21]. 
This formulation ensured a single phase after centrifugation at $4000 \times g$ for $15 \mathrm{~min}$ and storage for 30 days. In addition, the concentrations of LNEO in the nanoemulsions were similar to those in freshly prepared nanoemulsions after 30 days of storage. Furthermore, the mean particle size and PDI did not change during storage period. These results showed that the nanoemulsion formulated by LNEO, ethanol, Tween 80 and the aqueous phase was stable.

\subsection{Changes in Firmness, Lightness and Browning Index in Fresh-Cut Muskmelons}

Table 1 shows the changes in the firmness, lightness and browning index of fresh-cut muskmelons uncoated and coated with LNEO nanoemulsions during storage. Interestingly, the LNEO nanoemulsion coating had no significant influence $(p>0.05)$ on the firmness of muskmelon slices during storage time. No considerable change in the firmness of the fresh-cut muskmelons was found during storage with LNEO nanoemulsion, and the values ranged from $11.72 \pm 1.01 \mathrm{~kg}$ to $11.55 \pm 0.79 \mathrm{~kg}$. In addition, no softening of control fresh-cut muskmelons was observed during storage, and the values ranged from $11.76 \pm 1.12 \mathrm{~kg}$ to $11.29 \pm 0.84 \mathrm{~kg}$. Thus, coating with the LNEO nanoemulsion had no contribution to the retention of the firmness of the fresh-cut muskmelon slices. Salvia-Trujillo et al. [7] found that lemongrass essential oil (LEO) nanoemulsions as edible coatings had no influence on the firmness of fresh-cut apples. However, fruit softens after coating with edible essential oil $[11,22]$. Loss of hardness can be attributed to the low $\mathrm{pH}$ of a film-forming solution and leads to the acid hydrolysis of pectinic acid in fruit cells [23]. The degradation of texture may be due to structural changes because essential oil penetrated into the cell tissues of fruit [24]. The difference between this study and the previously reports may depend on the high initial hardness value of melon slices and the inherent variety hardness characteristics. Interestingly, the firmness of fresh-cut muskmelons coated with a microencapsulated $\beta$ cyclodextrin/trans-cinnamaldehyde complex in chitosan matrix was significantly firmer throughout storage, possibly owing to the cross-linking phenomenon [25].

Table 1. Effects of LNEO nanoemulsion on firmness, lightness and browning index in fresh-cut muskmelons.

\begin{tabular}{ccccccc}
\hline \multirow{2}{*}{$\begin{array}{c}\text { Storage } \\
\text { Time } \\
\text { (Days) }\end{array}$} & Control & $\begin{array}{c}\text { LNEO } \\
\text { Nanoemulsion }\end{array}$ & Control & $\begin{array}{c}\text { LNEO } \\
\text { Nanoemulsion }\end{array}$ & Control & $\begin{array}{c}\text { Lightness }\left(L^{*}\right) \\
\text { Nanoemulsion }\end{array}$ \\
\cline { 2 - 7 } & $11.76 \pm 1.12$ & $11.72 \pm 1.01$ & $72.66 \pm 2.27$ & $71.97 \pm 2.17$ & $0.067 \pm 0.003$ & $0.077 \pm 0.002$ \\
\hline 0 & $11.70 \pm 1.07$ & $11.71 \pm 1.03$ & $69.12 \pm 2.80$ & $70.66 \pm 2.46$ & $0.094 \pm 0.005$ & $0.078 \pm 0.004$ \\
\hline 2 & $11.59 \pm 0.73$ & $11.67 \pm 1.03$ & $68.91 \pm 3.11$ & $69.35 \pm 1.64$ & $0.136 \pm 0.009^{\mathrm{a}}$ & $0.084 \pm 0.006^{\mathrm{b}}$ \\
\hline 4 & $11.48 \pm 1.01$ & $11.61 \pm 0.76$ & $65.20 \pm 2.91$ & $67.98 \pm 1.82$ & $0.193 \pm 0.014^{\mathrm{a}}$ & $0.087 \pm 0.003^{\mathrm{b}}$ \\
\hline 6 & $11.29 \pm 0.84$ & $11.55 \pm 0.79$ & $60.35 \pm 2.73$ & $66.04 \pm 1.93$ & $0.314 \pm 0.018^{\mathrm{a}}$ & $0.095 \pm 0.007^{\mathrm{b}}$ \\
\hline 8 & &
\end{tabular}

$\overline{\mathrm{a}, \mathrm{b}}$ Data are the mean \pm standard deviation $(\mathrm{n}=3)$; ${ }^{\mathrm{a}, \mathrm{b}}$ different letters in the same index denote statistical significance.

The discoloration of fresh-cut muskmelons is the common factor limiting shelf life and marketability [1]. Low $L^{* *}$ values indicated increase in the degree of browning discolouration. $L^{* *}$ values of fresh-cut muskmelons was decreased throughout the storage in in control and treated slices of muskmelons. The results revealed that the $L^{* *}$ values in the slices treated with LNEO nanoemulsion decreased by $8.24 \%$, but the slices in the control samples decreased by $16.94 \%$ at the end of the storage period. Whereas, there was no significant influence $(p>0.05)$ on the lightness of muskmelon slices for two treatments. The $L^{*}$ values of fresh-cut muskmelons coated with a microencapsulated $\beta$-cyclodextrin/transcinnamaldehyde complex in chitosan matrix were higher than those of the controls by the end of storage time [25]. Cut browning is the major constraint on the processing and sale of fresh-cut produce, such as muskmelons. The browning index of the control slices increased significantly relative to that in the LNEO nanoemulsion slices $(p<0.05)$. Naeem et al. [11] found that mangoes with edible coatings supplemented with essential oils including LNEO 
had significantly low browning indices. The colors of muskmelon slices can be affected by different mechanisms: nonenzymatic browning due to the degradation of ascorbic acid, acid-catalysed degradation of sugars and Maillard reactions between reducing sugars and amino acids and enzymatic browning by PPO and POX, which are the major deteriorative reactions during storage [26]. Edible coatings can retard enzymatic browning due to their oxygen barrier properties [8]. Therefore, the use of LNEO nanoemulsion has an effect on color maintenance in fresh-cut muskmelons.

\subsection{Changes in Total Soluble Solids and Titratable Acidity in Fresh-Cut Muskmelons}

Changes in the TSS, TA and TSS/TA of fresh-cut muskmelon slices during storage are shown in Table 2. The TSS content of the uncoated fresh-cut muskmelons remained constant throughout the storage period, consistent with previous reports [11,27] and is not significantly different $(p>0.05)$ from the TSS content in the coated samples. Nevertheless, the TSS content in fresh-cut muskmelons coated with a microencapsulated $\beta$-cyclodextrin/transcinnamaldehyde complex in chitosan matrix was higher than that in the controls [25]. However, TA showed a declining trend during storage. TA in the control slices decreased by $54.54 \%$ at the end of the storage. Meanwhile, TA in the slices treated with LNEO nanoemulsion significantly decreased $(37.50 \%)$ relative to that in the control sample $(p<0.05)$. Similar observations were reported in previous works [11,25]. Compared to the first day, the TSS/TA ratio increased for both treatments. The TSS/TA ratio of the control group was higher than that of the LNEO nanoemulsion-treated samples. A significant difference $(p<0.05)$ was found during storage. Change in TSS/TA ratio showed that the taste of the fresh-cut muskmelons had changed during storage [27]. The result revealed that LNEO nanoemulsion affected the taste of the fresh-cut muskmelons.

Table 2. Effects of the LNEO nanoemulsion on TSS and TA content in fresh-cut muskmelons.

\begin{tabular}{ccccccc}
\hline $\begin{array}{c}\text { Storage } \\
\text { Time } \\
\text { (Days) }\end{array}$ & Control & $\begin{array}{c}\text { TNEO } \\
\text { Nanoemulsion }\end{array}$ & Control & $\begin{array}{c}\text { LNEO } \\
\text { Nanoemulsion }\end{array}$ & Control & $\begin{array}{c}\text { LNEO } \\
\text { Nanoemulsion }\end{array}$ \\
\cline { 2 - 7 } & $13.31 \pm 0.70$ & $13.37 \pm 0.55$ & $0.22 \pm 0.02$ & $0.22 \pm 0.02$ & $60.50 \pm 5.47$ & $60.77 \pm 4.74$ \\
\hline 0 & $13.23 \pm 0.40$ & $13.27 \pm 0.23$ & $0.20 \pm 0.01$ & $0.21 \pm 0.02$ & $66.15 \pm 4.12$ & $62.71 \pm 2.66$ \\
\hline 2 & $13.06 \pm 0.44$ & $13.17 \pm 0.38$ & $0.17 \pm 0.02$ & $0.20 \pm 0.02$ & $76.82 \pm 4.78$ & $65.15 \pm 3.45$ \\
\hline 4 & $12.86 \pm 0.15$ & $13.03 \pm 0.38$ & $0.13 \pm 0.01^{\mathrm{b}}$ & $0.18 \pm 0.01^{\mathrm{a}}$ & $98.92 \pm 1.76^{\mathrm{b}}$ & $71.00 \pm 2.65^{\mathrm{a}}$ \\
\hline 6 & $12.78 \pm 0.32$ & $12.96 \pm 0.46$ & $0.10 \pm 0.00^{\mathrm{b}}$ & $0.16 \pm 0.01^{\mathrm{a}}$ & $127.8 \pm 3.84^{\mathrm{b}}$ & $79.75 \pm 4.62^{\mathrm{a}}$ \\
\hline 8 & & & & \multicolumn{2}{c}{ TA (\%) } & \multicolumn{2}{c}{ TSS/TA Ratio } \\
\hline
\end{tabular}

$\mathrm{a}, \mathrm{b}$ Data are the mean \pm standard deviation $(\mathrm{n}=3){ }^{\mathrm{a}, \mathrm{b}}$ different letters in the same index denote statistical significance.

\subsection{Changes in the Activities of PPO, POX and PAL and Their Relationship with TPC}

The cutting of muskmelon fruit accelarates enzymatic browning, which would lead to economic loss. The rate of enzymatic browning depends on the $\mathrm{pH}$, ascorbic acid, total phenolics, temperature, active PPO content and oxygen availability in tissues [14]. Changes in TPC in both treatments throughout the storage period are shown in Figure 2a. The total phenolics content of fresh-cut muskmelons was parallel to that in the uncoated and nanoemulsion-coated muskmelons in the initial day. Owing to wounding, TPC declined by $41.63 \%$ in the uncoated muskmelon slices during storage. The decline in the coated slices at 8 days of storage was lower (31.95\%). The decrease in TPC during storage of fresh-cut muskmelons may be due to the oxidation of PPO enzymes. Changes in the TPC and PPO activity in LNEO nanoemulsion and the control showed similar trends during the experiment period. PPO activity increased abruptly by $89.30 \%$ in the control but increased only by $15.31 \%$ in the coated slices after 2 days of storage (Figure 2 b). Finally, PPO activity in the uncoated muskmelon slices was approximately two fold that in the coated slices. With the prolongation of storage time, the effects of PPO activity and TPC value of fresh-cut muskmelon slices on storage time indicated that the LNEO nanoemulsion treatment could effectively reduce the occurrence of browning. The effects of PPO activity and TPC on the degree of browning in muskmelon fruit were significantly different $(p<0.05)$ [14] 
Similar, the relationship between TPC and PPO activity was also found by Sharma and Rao (2015) [14]. Since POX has the ability to accept a wide range of hydrogen donors, such as polyphenols, it is known to enzymatic browning of fresh-cut fruit [28]. Figure 2c shows that the initial POX activity of the control samples was comparable to LNEO nanoemulsion samples (4.450 \pm 0.591 and $4.333 \pm 0.501 \mathrm{U} / g$ protein, respectively) and then increased constantly in storage time. At the end of the storage period, the POX activity of the uncoated samples was $25.37 \%$ higher than that of the coated samples. Whereas, the relative level of oxidative stress mediated by the production of free radical species might result in the overall continuous increase in POX activity of fresh-cut muskmelons during storage [29]. PAL is the catalyst for the initial step in phenylpropanoid biosynthesis, followed by the formation of a variety of phenolic compounds [30]. PAL activity in uncoated fresh-cut slices declined gradually in the storage period, which ranged from $2.085 \pm 0.158 \mathrm{U} / \mathrm{g}$ protein to $0.823 \pm 0.088 \mathrm{U} / \mathrm{g}$ protein (Figure $2 \mathrm{~d}$ ). However, PAL activity in the coated fresh-cut slices remained stable within 6 days of storage and then showed a decrease in the end of storage. Sharma and Rao [14] reported that the reduction of PAL activity was comparatively faster in control than that of fresh-cut pears with edible coating. Therefore, our results reveal that LNEO nanoemulsion could significantly inhibit the decrease in PAL activity $(p<0.05)$. The low activities of PPO and PAL in muskmelon slices coated with LNEO nanoemulsion might relieve the browning of the fresh-cut muskmelons.
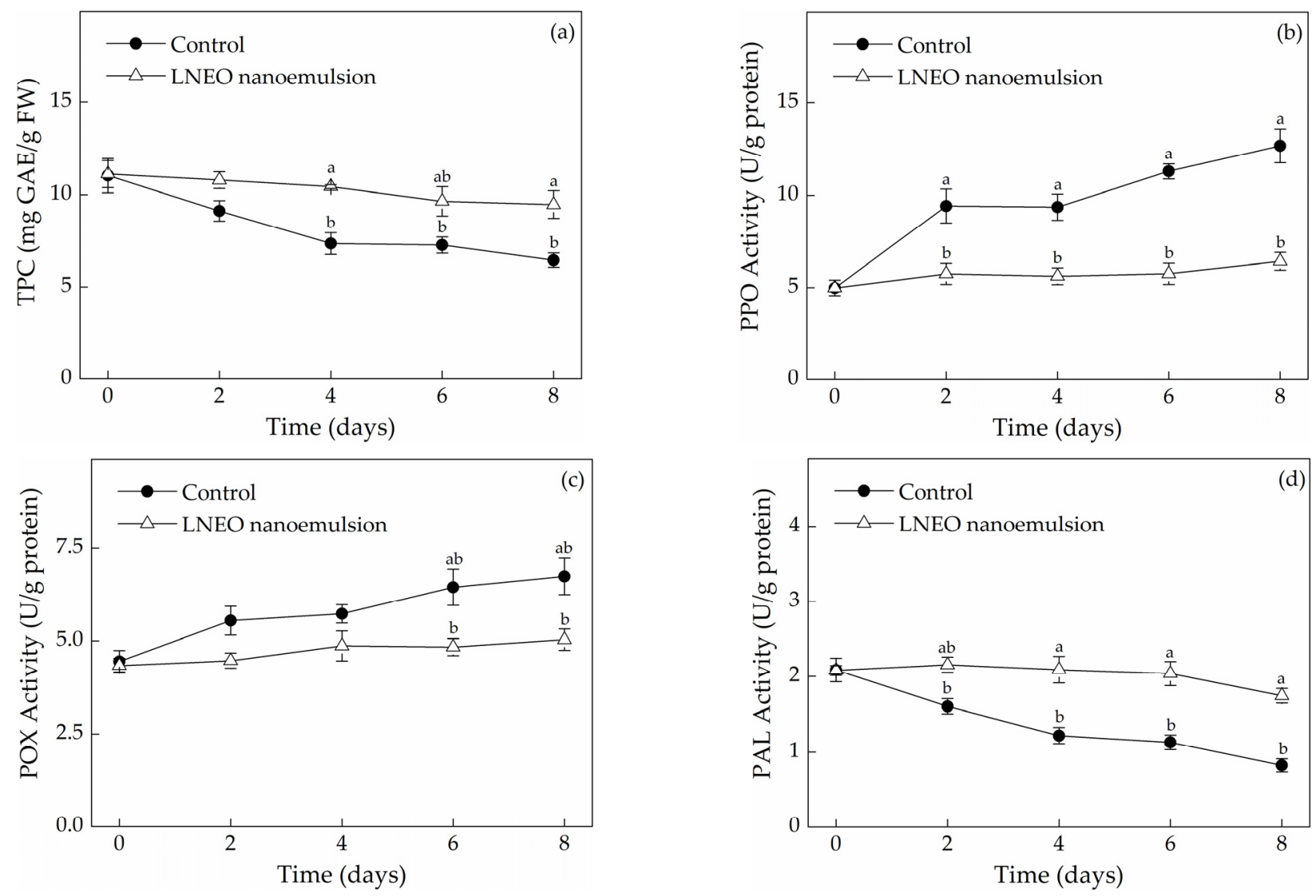

Figure 2. Effects of the LNEO nanoemulsion on TPC (a) and activities of PPO (b), POX (c) and PAL (d) in fresh-cut muskmelons. Data are the mean \pm standard deviation $(n=3) ; a, b$ different letters denote statistical significance.

\subsection{Changes in the Activities of POD and CAT in Fresh-Cut Muskmelons}

The activities of enzymes (POD and CAT) related to the antioxidant system in fresh-cut muskmelons are shown in Figure 3. Antioxidant system can protect against oxidative stress and delay fruit senescence. Increases in the activity levels of POD and CAT antioxidant enzymes lead to an increase in reactive oxygen species (ROS), thereby reducing fruit 
quality [31]. Figure 3 shows that in both muskmelon samples, activities of POD and CAT increased during 8 days of storage. It was speculated that the increase in activities of antioxidant enzyme was related to the mechanical damage to muskmelons during fresh-cutting. However, the POD activity of the LNEO nanoemulsion-treated samples was significantly lower than that of the control during storage $(p<0.05)$. As shown in Figure $3 a$, the activities of POD in the uncoated and coated samples after 8 days of storage was $33.12 \pm 2.42$ and $18.45 \pm 1.82 \mathrm{U} / \mathrm{g}$ protein, respectively. At the end of storage, the POD activity of the control sample was 1.80 times that of the LNEO nanoemulsion treatment. The CAT exhibited the same activity trends as POD. The CAT activity of the LNEO nanoemulsion-treated samples was significantly lower than that of the control throughout the storage process $(p<0.05$; Figure $3 b)$. As shown in Figure $3 b$, the activities of CAT in the uncoated and coated samples during 8 days of storage were $19.39 \pm 1.50$ and $9.367 \pm 0.913 \mathrm{U} / \mathrm{g}$ protein, respectively. At the end of storage, the activity of the control sample was 2.07 times higher than that of the LNEO nanoemulsion treatment. Owing to the inhibition of antioxidative enzyme activities (CAT and POD) possibly by the antioxidant activity of LNEO [32], the LNEO nanoemulsion treatment maintained the antioxidant system of the fresh-cut muskmelons to a certain extent.
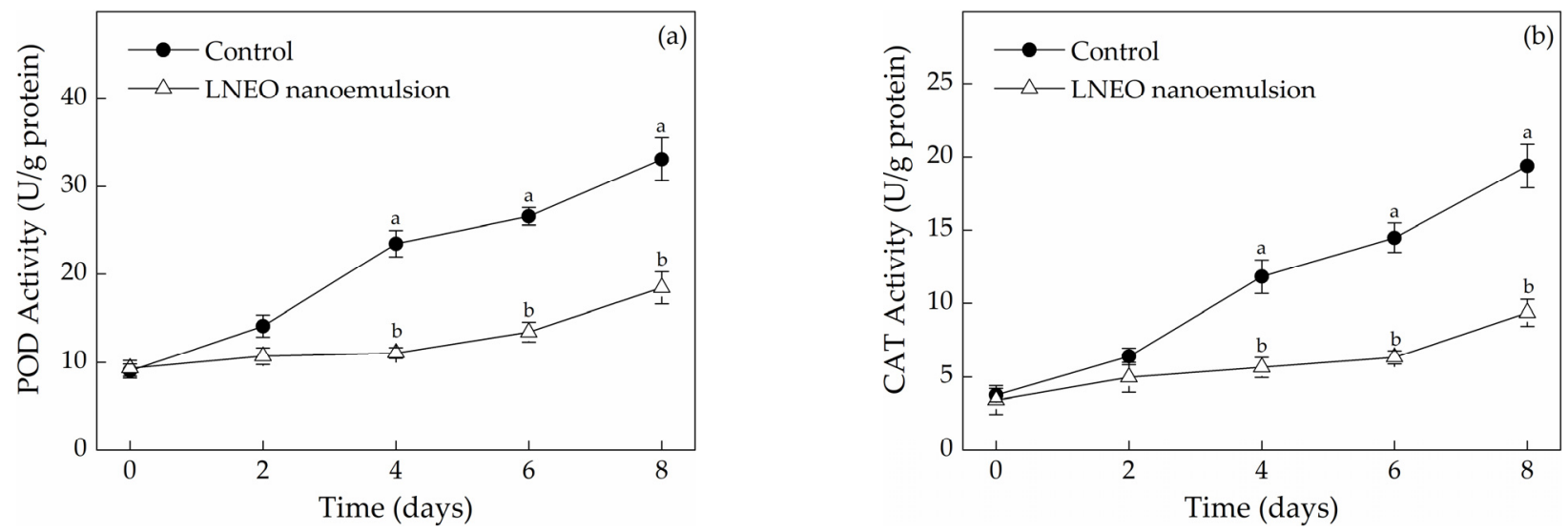

Figure 3. Effects of the LNEO nanoemulsion on activities of POD (a) and CAT (b) in fresh-cut muskmelons. Data are the mean \pm standard deviation $(n=3) ; a, b$ different letters denote statistical significance.

\subsection{Microbial Growth in Fresh-Cut Muskmelons}

The microbial biomass of muskmelons is one of the important indexes for evaluating storage attributes. Operations, such as peeling, cutting and slicing, greatly increase the risk of microbial growth [15]. Consumers typically detect spoilage in fresh-cut fruit and vegetables when the aerobic microorganisms, yeasts and molds are above 7 and 5 log $\mathrm{CFU} / \mathrm{g}$, respectively, on fresh-cut fruit or vegetables [15]. As shown in Figure 4, microbial growth in both treatments gradually increased with prolonged storage time. However, the total number of aerobic bacteria in the LNEO nanoemulsion-treated samples was significantly lower than that in the control group during storage $(p<0.05)$. The total number of aerobic bacteria in the LNEO nanoemulsion-treated muskmelon samples was $5.14 \pm 0.47$ $\log \mathrm{CFU} / \mathrm{g}$ FW on days 8, whereas that of the control was $9.42 \pm 0.88 \log$ CFU/g FW (Figure $4 \mathrm{a}$ ). The aerobic plate counts of fresh-cut melons coated with a microencapsulated $\beta$-cyclodextrin/trans-cinnamaldehyde complex in chitosan matrix were lower than those of the controls [25]. After 8 days of storage, in the fresh-cut muskmelons treated with LNEO nanoemulsion, the population of molds and yeasts was $3.12 \pm 0.22 \log$ CFU/g FW. In the control population of molds and yeasts, the aerobic plate count was $5.24 \pm 0.34 \log$ $\mathrm{CFU} / \mathrm{g}$ FW (Figure $4 \mathrm{~b}$ ). The use of lemongrass essential oil did not exhibit a fungistatic effect on yeast-mold populations in melons [33]. The different research results might be due to the type of essential oil. Thus, LNEO nanoemulsion treatment had a major role in 
the restraining of microorganism growth. LNEO nanoemulsion treatment was effective in inhibiting microbial growth possibly because LNEO contains strong antibacterial activities that decrease the growth of microorganisms [9,32]. In addition, the application of thyme essential oil and verbenaone as antibacterial agents successfully reduced the growth of Listeria monocytogenes on fresh-cut melons [34].
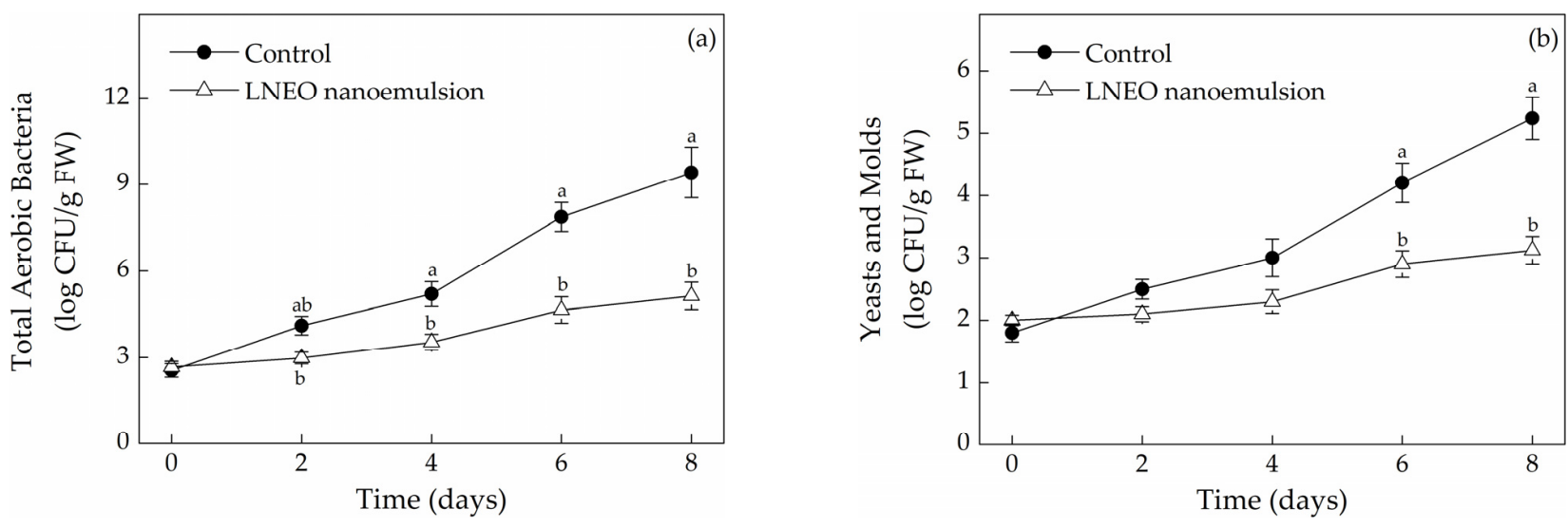

Figure 4. Effects of the LNEO nanoemulsion on the microbial growth (log CFU/g FW) in fresh-cut muskmelons: total aerobic bacteria $(\mathbf{a})$; molds and yeasts $(\mathbf{b})$. Data are the mean \pm standard deviation $(\mathrm{n}=3) ; \mathrm{a}$, b different letters denote statistical significance.

\section{Conclusions}

The prepared nanoemulsion was composed of water aqueous $(99 \% w / w)$, Tween $80(0.6 \%$ $w / w)$, ethanol $(0.3 \% w / w)$ and LNEO $(0.1 \% w / w)$ with $23.57 \pm 0.61 \mathrm{~nm}$ particle size. An LNEO nanoemulsion coating method retarded oxidative browning and decreased the TA level. The browning index in the slices treated with the LNEO nanoemulsion was $0.095 \pm 0.007$, as compared with $0.314 \pm 0.018$ in the slices of the control samples at the end of storage period. LNEO nanoemulsion coating maintained TPC with values ranging from $11.13 \pm 0.74 \mathrm{mg}$ GAE/g FW to $9.47 \pm 0.75 \mathrm{mg}$ GAE/g FW. Meanwhile, coating with LNEO nanoemulsion inhibited the activities of browning related enzymes (PPO and POX), thereby preventing the oxidation of total phenolics and delayed browning. Furthermore, the application of LNEO nanoemulsion inhibited the activities of POD and CAT and inhibited the proliferation of spoilage microorganisms. The populations of total aerobic bacteria as well as molds and yeasts in the muskmelon samples after 8 days of storage after LNEO nanoemulsion treatment were $5.14 \pm 0.47$ and $3.12 \pm 0.22 \log \mathrm{CFU} / \mathrm{g}$ FW, whereas those in the control were $9.42 \pm 0.88$ and $5.24 \pm 0.34 \log$ CFU/g FW, respectively. Given that the LNEO nanoemulsion was found to maintain the physiological quality of fresh-cut muskmelons, LNEO nanoemulsion coating is effective in preserving fresh-cut muskmelons. Further studies are needed to establish the efficacy of LNEO nanoemulsion in improving the quality of other fresh fruit and fresh-cut products.

Author Contributions: Conceptualization, Q.R. and Q.H.; methodology, Q.R.; software, X.Z.; validation, Q.R., Q.H. and C.D.; formal analysis, C.D.; investigation, Q.R.; resources, Q.R.; data curation, Q.R.; writing—original draft preparation, Q.R.; writing—review and editing, Q.H. and C.D.; visualization, Y.W.; supervision, Q.H.; project administration, Q.R.; funding acquisition, Q.R. All authors have read and agreed to the published version of the manuscript.

Funding: The authors are grateful to the Public Projects of Zhejiang Province (2016C32001) and Hangzhou Agricultural Research Project (20191203B31) for their support.

Institutional Review Board Statement: Not applicable.

Informed Consent Statement: Not applicable.

Data Availability Statement: Data sharing is not applicable for this article.

Conflicts of Interest: The authors declare no conflict of interest. 


\section{References}

1. Barrett, D.M.; Beaulieu, J.C.; Shewfelt, R. Color, Flavor, Texture, and Nutritional Quality of Fresh-Cut Fruits and Vegetables: Desirable Levels, Instrumental and Sensory Measurement, and the Effects of Processing. Crit. Rev. Food Sci. Nutr. 2010, 50, 369-389. [CrossRef] [PubMed]

2. Panahirad, S.; Dadpour, M.; Peighambardoust, S.H.; Soltanzadeh, M.; Gullón, B.; Alirezalu, K.; Lorenzo, J.M. Applications of carboxymethyl cellulose- and pectin-based active edible coatings in preservation of fruits and vegetables: A review. Trends Food Sci. Technol. 2021, 110, 663-673. [CrossRef]

3. Ma, Q.; Davidson, P.M.; Zhong, Q. Antimicrobial properties of microemulsions formulated with essential oils, soybean oil, and Tween 80. Int. J. Food Microbiol. 2016, 226, 20-25. [CrossRef] [PubMed]

4. Prakash, B.; Kujur, A.; Yadav, A.; Kumar, A.; Singh, P.P.; Dubey, N.K. Nanoencapsulation: An efficient technology to boost the antimicrobial potential of plant essential oils in food system. Food Control 2018, 89, 1-11. [CrossRef]

5. Park, J.-B.; Kang, J.-H.; Song, K.B. Clove bud essential oil emulsion containing benzethonium chloride inactivates Salmonella Typhimurium and Listeria monocytogenes on fresh-cut pak choi during modified atmosphere storage. Food Control 2019, 100, 17-23. [CrossRef]

6. Sathiyaseelan, A.; Saravanakumar, K.; Mariadoss, A.V.A.; Ramachandran, C.; Hu, X.; Oh, D.-H.; Wang, M.-H. Chitosan-tea tree oil nanoemulsion and calcium chloride tailored edible coating increase the shelf life of fresh cut red bell pepper. Prog. Org. Coat. 2021, 151, 106010. [CrossRef]

7. Salvia-Trujillo, L.; Rojas-Graü, M.A.; Soliva-Fortuny, R.; Martín-Belloso, O. Use of antimicrobial nanoemulsions as edible coatings: Impact on safety and quality attributes of fresh-cut Fuji apples. Postharvest Biol. Technol. 2015, 105, 8-16. [CrossRef]

8. Radi, M.; Akhavan-Darabi, S.; Akhavan, H.-R.; Amiri, S. The use of orange peel essential oil microemulsion and nanoemulsion in pectin-based coating to extend the shelf life of fresh-cut orange. J. Food Process. Preserv. 2018, 42, e13441. [CrossRef]

9. Lima Reis, P.M.C.; Mezzomo, N.; Aguiar, G.P.S.; Hotza, D.; Baggio Ribeiro, D.H.; Salvador Ferreira, S.R.; Hense, H. Formation, stability and antimicrobial activity of laurel leaves essential oil (Laurus nobilis L.) particles in suspension obtained by SFEE. J. Supercrit. Fluids 2020, 166, 105032. [CrossRef]

10. Stefanova, G.; Girova, T.; Gochev, V.; Stoyanova, M.; Petkova, Z.; Stoyanova, A.; Zheljazkov, V.D. Comparative study on the chemical composition of laurel (Laurus nobilis L.) leaves from Greece and Georgia and the antibacterial activity of their essential oil. Heliyon 2020, 6, e05491. [CrossRef]

11. Naeem, A.; Abbas, T.; Ali, T.M.; Hasnain, A. Effect of guar gum coatings containing essential oils on shelf life and nutritional quality of green-unripe mangoes during low temperature storage. Int. J. Biol. Macromol. 2018, 113, 403-410. [CrossRef] [PubMed]

12. Xu, S.; Ni, Z.; Ma, L.; Zheng, X. Control of alternaria rot of cherry tomatoes by food-grade Laurus nobilis essential oil microemulsion. J. Food Saf. 2017, 37, e12286. [CrossRef]

13. Saxena, A.; Bawa, A.S.; Raju, P.S. Effect of minimal processing on quality of jackfruit (Artocarpus heterophyllus L.) bulbs using response surface methodology. Food Bioprocess Technol. 2012, 5, 348-358. [CrossRef]

14. Sharma, S.; Rao, T.V.R. Xanthan gum based edible coating enriched with cinnamic acid prevents browning and extends the shelf-life of fresh-cut pears. LWT Food Sci. Technol. 2015, 62, 791-800. [CrossRef]

15. Xu, M.; Liu, H.; Huang, M.; Zhou, D.; Cao, Q.; Ma, K. Effects of high pressure nitrogen treatments on the quality of fresh-cut pears at cold storage. Innov. Food Sci. Emerg. Technol. 2015, 32, 56-63. [CrossRef]

16. Zhu, Z.; Zhan, L. Characterization of polyphenoloxidase from water Caltrop (Trapa acornis Nakano) fruits. J. Food Biochem. 2010, 34, 1125-1140. [CrossRef]

17. Bradford, M.M. A rapid and sensitive method for the quantitation of microgram quantities of protein utilizing the principle of protein-dye binding. Anal. Biochem. 1976, 72, 248-254. [CrossRef]

18. Prakash, A.; Baskaran, R.; Vadivel, V. Citral nanoemulsion incorporated edible coating to extend the shelf life of fresh cut pineapples. LWT 2020, 118, 108851. [CrossRef]

19. Zhang, S.; Zhang, M.; Fang, Z.; Liu, Y. Preparation and characterization of blended cloves/cinnamon essential oil nanoemulsions. LWT 2017, 75, 316-322. [CrossRef]

20. Huang, Z.; Liu, X.; Jia, S.; Luo, Y. Antimicrobial effects of cinnamon bark oil on microbial composition and quality of grass carp (Ctenopharyngodon idellus) fillets during chilled storage. Food Control 2017, 82, 316-324. [CrossRef]

21. Du, Z.; Mao, X.; Tai, X.; Wang, G.; Liu, X. Preparation and properties of microemulsion detergent with linear medium chain fatty alcohols as oil phase. J. Mol. Liq. 2016, 223, 805-810. [CrossRef]

22. Raybaudi-Massilia, R.M.; Rojas-Graü, M.A.; Mosqueda-Melgar, J.; Martín-Belloso, O. Comparative study on essential oils incorporated into an alginate-based edible coating to assure the safety and quality of fresh-cut Fuji apples. J. Food Prot. 2008, 71, 1150-1161. [CrossRef] [PubMed]

23. Ponting, J.D.; Jackson, R.; Watters, G. Refrigerated apple slices: Effects of pH, sulfites and calcium on texture. J. Food Sci. 1971, 36, 349-350. [CrossRef]

24. Sánchez-González, L.; Vargas, M.; González-Martínez, C.; Chiralt, A.; Cháfer, M. Use of essential oils in bioactive edible coatings: A review. Food Eng. Rev. 2011, 3, 1-16. [CrossRef]

25. Moreira, S.P.; de Carvalho, W.M.; Alexandrino, A.C.; de Paula, H.C.B.; Rodrigues, M.d.C.P.; de Figueiredo, R.W.; Maia, G.A.; de Figueiredo, E.M.A.T.; Brasil, I.M. Freshness retention of minimally processed melon using different packages and multilayered edible coating containing microencapsulated essential oil. Int. J. Food Sci. Technol. 2014, 49, 2192-2203. [CrossRef] 
26. Wibowo, S.; Grauwet, T.; Santiago, J.S.; Tomic, J.; Vervoort, L.; Hendrickx, M.; Van Loey, A. Quality changes of pasteurised orange juice during storage: A kinetic study of specific parameters and their relation to colour instability. Food Chem. 2015, 187, 140-151. [CrossRef]

27. Supapvanich, S.; Tucker, G.A. The Effect of 1-methylcyclopropene (1-MCP) on quality and cell wall hydrolases activities of fresh-cut muskmelon (Cucumis melo var reticulatus L.) during storage. Food Bioprocess Technol. 2013, 6, 2196-2201. [CrossRef]

28. Koushesh Saba, M.; Moradi, S. Internal browning disorder of eight pear cultivars affected by bioactive constituents and enzyme activity. Food Chem. 2016, 205, 257-263. [CrossRef]

29. Lamikanra, O.; Watson, M.A. Cantaloupe melon peroxidase: Characterization and effects of additives on activity. Food Nahr. 2000, 44, 168-172. [CrossRef]

30. Dong, T.; Shi, J.; Jiang, C.-Z.; Feng, Y.; Cao, Y.; Wang, Q. A short-term carbon dioxide treatment inhibits the browning of fresh-cut burdock. Postharvest Biol. Technol. 2015, 110, 96-102. [CrossRef]

31. Hu, Y.; Hao, Y.; Wei, Z.; Cui, H.; Zhan, Y. Effect of 1-MCP coupling with carbon dioxide treatment on antioxidant enzyme activities and quality of fresh-cut Fuji apples. J. Food Process. Preserv. 2020, 44, e14903. [CrossRef]

32. Ramos, C.; Teixeira, B.; Batista, I.; Matos, O.; Serrano, C.; Neng, N.R.; Nogueira, J.M.F.; Nunes, M.L.; Marques, A. Antioxidant and antibacterial activity of essential oil and extracts of bay laurel Laurus nobilis Linnaeus (Lauraceae) from Portugal. Nat. Prod. Res. 2012, 26, 518-529. [CrossRef] [PubMed]

33. Hadjilouka, A.; Polychronopoulou, M.; Paramithiotis, S.; Tzamalis, P.; Drosinos, E.H. Effect of lemongrass essential oil vapors on microbial dynamics and Listeria monocytogenes survival on rocket and melon stored under different packaging conditions and temperatures. Microorganisms 2015, 3, 535-550. [CrossRef] [PubMed]

34. Scollard, J.; McManamon, O.; Schmalenberger, A. Inhibition of Listeria monocytogenes growth on fresh-cut produce with thyme essential oil and essential oil compound verbenone. Postharvest Biol. Technol. 2016, 120, 61-68. [CrossRef] 